\title{
Tissue Regeneration without Scarring Achieved by Enhancing the Alternative Cellular Energy (ACE) Pathway
}

\author{
W. John Martin \\ Institute of Progressive Medicine, South Pasadena, CA, USA \\ Email: wjohnmartin@ccid.org
}

How to cite this paper: Martin, W.J. (2017) Tissue Regeneration without Scarring Achieved by Enhancing the Alternative Cellular Energy (ACE) Pathway. Journal of Cosmetics, Dermatological Sciences and Applications, 7, 82-98.

https://doi.org/10.4236/jcdsa.2017.71009

Received: February 15, 2017

Accepted: March 19, 2017

Published: March 22, 2017

Copyright $\odot 2017$ by author and Scientific Research Publishing Inc. This work is licensed under the Creative Commons Attribution-NonCommercial International License (CC BY-NC 4.0). http://creativecommons.org/licenses/by-nc/4.0

Open Access

\begin{abstract}
The inflammatory and fibrous responses to injuries are painful and are inhibitory to the regeneration of specialized cells. The fibrous scarring of skin injuries can also be disfiguring. Cells obtain energy not only from the metabolism of food, but also via the alternative cellular energy (ACE) pathway. The ACE pathway is reflected in a dynamic (kinetic) quality of the body's fluids. It is postulated to result from the absorption of an environmental force called KELEA (kinetic energy limiting electrostatic attraction). The body's ACE pathway can be enhanced by the parental administration and even the oral consumption of products comprising KELEA activated water. One of these products, termed Enercel, was originally considered a complex homeopathic remedy. Another product is water containing electrolysis-generated, coppersilver-citrate (CSC) complexes. This product was initially formulated to be bacteriocidal, especially for Gram positive bacteria. This article describes the independent successful use of each of these two products in achieving essentially painless, scar-free healing of skin injuries. The skin injuries were due to a variety of causes including: vascular insufficiency from diabetes; hot water burn; penetrating object; chronic infection; and surgical incision. It is proposed that the ACE pathway increases the resilience of cells of the innate immune system to the triggering of an inflammatory reaction by "danger signals" released from damaged tissues. KELEA activated water should be widely available for the urgent therapy of burns and other traumatic injuries to the skin. ACE pathway enhancing modalities also need to be evaluated in the repair of cellular damage occurring to the heart, brain and other internal organs of the body.
\end{abstract}

\section{Keywords}

Alternative Cellular Energy (ACE) Pathway, Insufficiency of Cellular Energy, 
ICE, Activated Water, KELEA, Kinetic Energy Limiting Electrostatic

Attraction, Enercel, Homeopathy, Copper, Silver, Burns, Scar, Diabetes, Innate Immunity, Danger Signals

\section{Introduction}

Cellular damage typically evokes an inflammatory response, which is followed by the production of fibrous tissue [1]. The inflammation is generally painful and can cause additional damage, especially to the more specialized cells within the damaged tissue. The amount of fibrous tissue formed will commonly exceed the amount previously present and comprise a scar. The scar can hinder the regenerative replacement of the specialized cells [2].

Chronic wounds arise when the inflammatory response persists and/or the regenerative process fails to occur [3]. Microbial infections can contribute to the continuing inflammation in chronic wounds, as can antibody and cell mediated auto-immunity [4].

Common causes of non-infectious tissue damage affecting the skin include burns, physical trauma, ischemia and operative incisions. In each case, released cellular materials trigger the "danger" response from the innate immune system [5]. This leads to an influx of fluid, complement proteins, and neutrophils from a leaking vasculature; with the purpose of digestion and removal of the damaged cells [6]. Fluid and other cellular infiltrations also allow for the sensing by antibodies and lymphocytes for the presence of microbial antigens. If these are present, the inflammatory reaction is expanded to involve the adaptive immune system [7]. Otherwise, after the removal of damaged cellular material, the next phase of healing is the influx of myofibroblasts [8]. These cells are mainly derived by the transformation of resident tissue fibroblasts, but can also arise from endothelial cells in penetrating capillaries [9] and from circulating bone marrow-derived fibrocyte cells [10]. The myofibroblasts lead to the formation of extracellular collagen. They may also contract to reduce the distance between separated epithelial layers. Eventually, many of the myofibroblasts undergo death by apoptosis [11].

The loss of specialized cells also triggers a regenerative response aimed at restoring specialized cell numbers to preexisting levels [12]. This cellular replacement process is often incomplete due to interference by the inflammation and by the formation of fibrous tissue. Thus, for example, with major skin wounds, there is often a permanent loss of specialized structures, including sweat glands and hair follicles. The re-growing epithelial layer can also become irregular due to tissue loss and to outwardly protruding scars.

The healing process does not proceed beyond inflammation if there is an insufficient supply of blood, such that dying skin tissue continues to trigger the "danger" response [5]. This is commonly seen in the peripheral vascular disease of diabetes [13]. The healing process can also persist if contaminating microbes 
are not eliminated [14]. Various disorders have been ascribed to an excessive response by myofibroblasts [15]. The most notable is the formation of large, unsightly keloid scars and limitation of joint movement due to tissue contraction.

Tissue damage occurring in early embryos of several species including man is not accompanied by inflammation and myofibroblast activation [16] [17]. Accordingly, there is no scarring. It has, therefore, been proposed that anti-inflammatory therapy may help reduce the scarring that occurs in the injured skin of adults [18]. Indeed, as described in this paper, this can be achieved by employing products able to enhance cellular energy.

It had been assumed that cellular energy is only provided through the metabolism of food. Studies on a non-immunological anti-virus defense mechanism identified the survival of cells with markedly disrupted mitochondria [19]. Energy transducing, self-assembling, particulate materials are present in virus infected cells and in the extracellular fluids [20]. The materials are seemingly providing a non-mitochondrial or alternative source of cellular energy. Since they are commonly pigmented, they are termed alternative cellular energy (ACE) pigments [20].

Replacement of the tissue culture medium with regular medium leads to the rapid reactivation of the virus cytopathic effect (CPE). This reactivation does not occur if ACE pigments are added to the refeeding medium [20]. Reactivation of the CPE can similarly be inhibited by including small amounts of a homeopathic remedy termed Enercel in the refeeding material. Analysis of the components used to produce Enercel and of components present in various human health and agricultural promoting formulations, led to the conclusion that many dipolar chemical compounds can significantly increase the internal kinetic energy of fluids, including water. Additional inducible changes in "activated" fluids include greater volatility, lowered surface tension and lowered specific heat [21] [22] [23] [24] [25]. The changes are indicative of a loosening of intermolecular hydrogen bonding [25]. The fluid activation is attributed to the absorption of an external energy force called KELEA (kinetic energy limiting electrostatic attraction). The force is apparently attracted to the separated electrical charges on dipolar molecules. Some energy attracting dipolar chemicals can transfer the energy to nearby water molecules, possibly in an oscillatory manner. As discussed elsewhere, the fundamental role of KELEA in Nature is likely to be the prevention of fusion of electrostatically attracted opposite electrical charges. KELEA can also act at a distance. For example, KELEA energy fields can be generated by various electrical devices with rapid on-off switching or which force opposite electrical charges towards one another [26] [27].

Copper citrate and later copper-silver-citrate (CSC) solutions were initially developed for their potential use as environmental antibacterial fluids. Copper was chosen because of the sensitivity of Gram positive bacteria to the inhibitory effect of copper [28]. Silver was subsequently included to ensure coverage of Gram negative bacteria. Citric acid was chosen because of its chelating properties. Early studies showed that CSC had wound healing activities [29]. Later stu- 
dies showed that CSC could attract KELEA and activate added water.

Various clinical studies have been and are currently being conducted with Enercel, CSC and other sources of KELEA activated water. This paper highlights some of the striking findings with both Enercel and CSC with regards to wound healing in the absence of scarring.

\section{Materials and Methods}

CSC is produced from $5 \%$ citric acid solution buffered with potassium carbonate. Electrolysis of the solution is initially performed for 90 minutes using a silver anode and a copper cathode connected to a 12-volt DC power supply, delivering 7.0 to 7.5 Amperes. The silver anode is then replaced with a copper anode and the electrolysis continued for an additional 3 hours. These time periods for electrolysis achieve silver and copper concentrations of approximately $50 \mathrm{mg} / \mathrm{l}$ and $500 \mathrm{mg} / \mathrm{l}$, respectively. The final $\mathrm{pH}$ of the solution is adjusted to $\mathrm{pH} 4.0$ using citric acid. Unpublished nuclear magnetic resonance (NMR) studies are consistent with copper and silver atoms cross-linking with the carboxylic entities of multiple citrate molecules.

Enercel is described as a mixture of homeopathic dilutions at 1:10,000 (4X) of tinctures obtained from the following items: Cactus grandifloras, Aloe socotrina, Abies nigra, Amica montana, Lachesis mutus, Lycopodium clavatum and Calcium carbonate. It is prepared under Good Manufacturing Practice (GMP) conditions by World Health Advanced Technologies, Sarasota, FL. With minor adjustments, Enercel is prepared for intravenous, intramuscular and intranasal administration and as a spray-on mist (www.Enercel.com). The Enercel-mist is applied directly to the area of damaged skin.

CSC and Enercel have been characterized as KELEA activated water. This is based on their capacity in low amounts to increase the intrinsic kinetic activity and the volatility of added regular water. Various additional methods are available for producing high potency KELEA activated water and other solutions.

\section{Results}

\subsection{Enercel}

A 16-year-old girl received a blistering, painful, third degree burn to the dorsal surface of her left arm. It occurred from scalding by boiled water intended for preparing tea. She sought medical advice and was told by a physician that she would require a skin graft, to be obtained from her buttock. Upon returning home, the girl's mother photographed the arm (Figure 1) and began to copiously apply Enercel-mist over the entire burn area. This led to a substantial reduction in pain. The Enercel-mist spray was applied 30 minutes later and repeatedly over the next 48 hours. The physician was again consulted and confirmed that the skin was healing without evidence of infection (Figure 2). Over each of the next 6 days, in addition to the repeated spraying of Enercel-mist onto the area of burn, the girl received $50 \mathrm{ml}$ Enercel intravenously. A layer of dead tissue was 


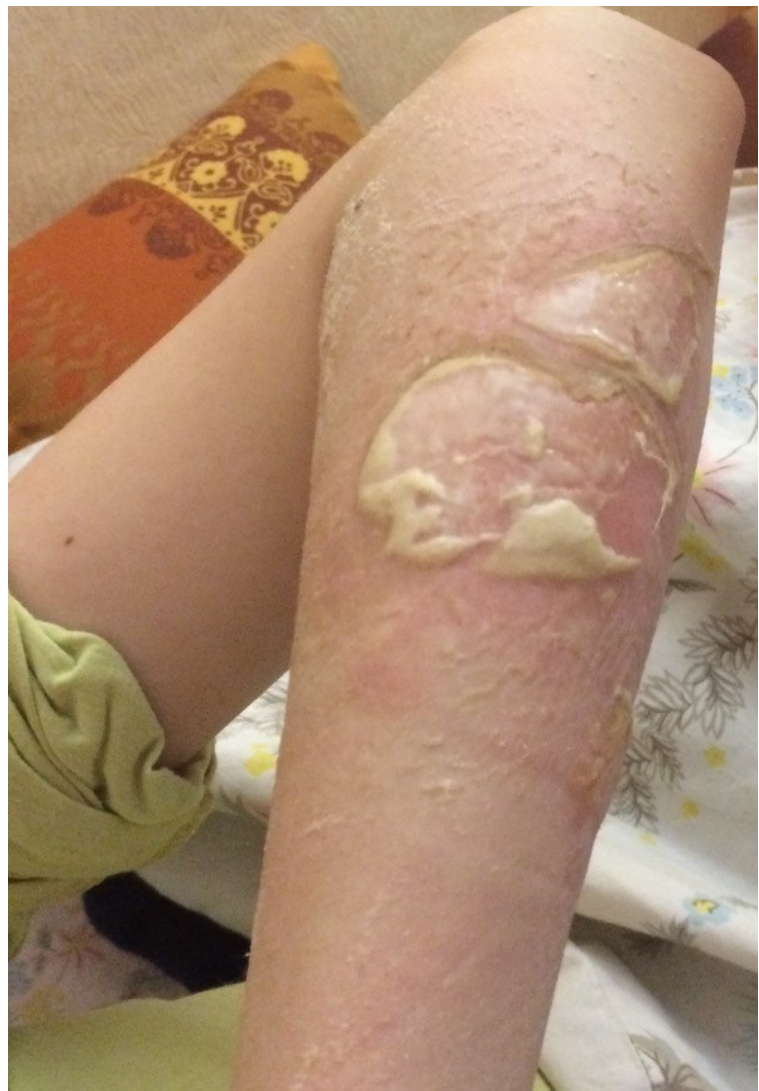

Figure 1. Severe skin blistering of the dorsal surface of the lower left arm resulting from scalding with boiled water. The photo was taken after the patient returned from a doctor's visit and prior to the application of Enercel-mist to the burn. It shows two central areas of third degree burns, surrounded by extensive areas of second degree burn.

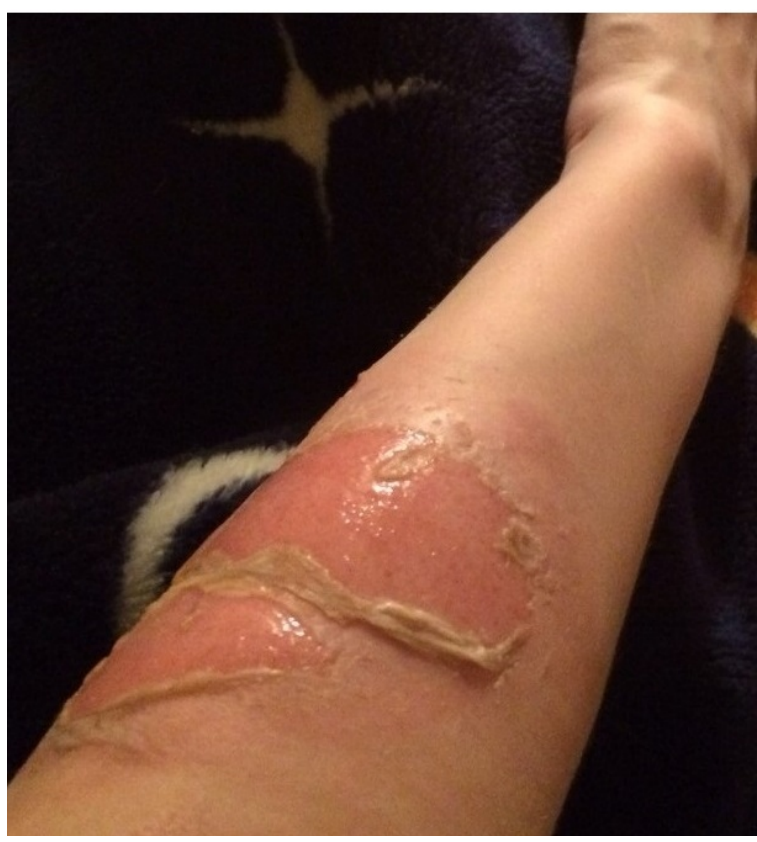

Figure 2. A photograph of the arm taken 2 days after the burn. The second degree burn areas have largely healed and the two third degree burn areas indicate healthy-looking underlying tissue. There are no indications of excessive inflammation. 
then gently scrapped from the burn site, revealing intact epithelium, overlaying what appeared to be mildly granulating soft tissue (Figure 3). The physician again advised skin grafting, but the girl and her mother declined. Instead, repeated local spaying of Enercel-mist was continued for the next several weeks. By 8 weeks, the burn area was near completely healed with only minimal tissue discoloration (Figure 4). The arm continued to heal with the return of hair and normal touch and pain sensitivity. There are no residual signs of the burn.

The lower left leg of a 79-year-old man with a long history of diabetes and hypertension became severely gangrenous due to prolonged ischemia (Figure 5). He was advised that he would surely die from the continuing tissue necrosis unless the leg was urgently amputated at the knee. Within 6 days, he learned of Enercel-mist and arranged for its repeated daily application to his leg. By 21 days, all necrotic tissue had sloughed off from the leg, revealing well-healing viable tissue (Figure 6). Intravenous injections of Enercel were then commenced as therapy for the patient's diabetes and hypertension. Local injections were also administered to an area in the patient's neck in which there was scar tissue from a previous laminectomy. The neck area was causing considerable pain and restricted the turning of his head. The medical conditions, as well as the leg ischemia have resolved, allowing the gentleman to resume an active lifestyle.

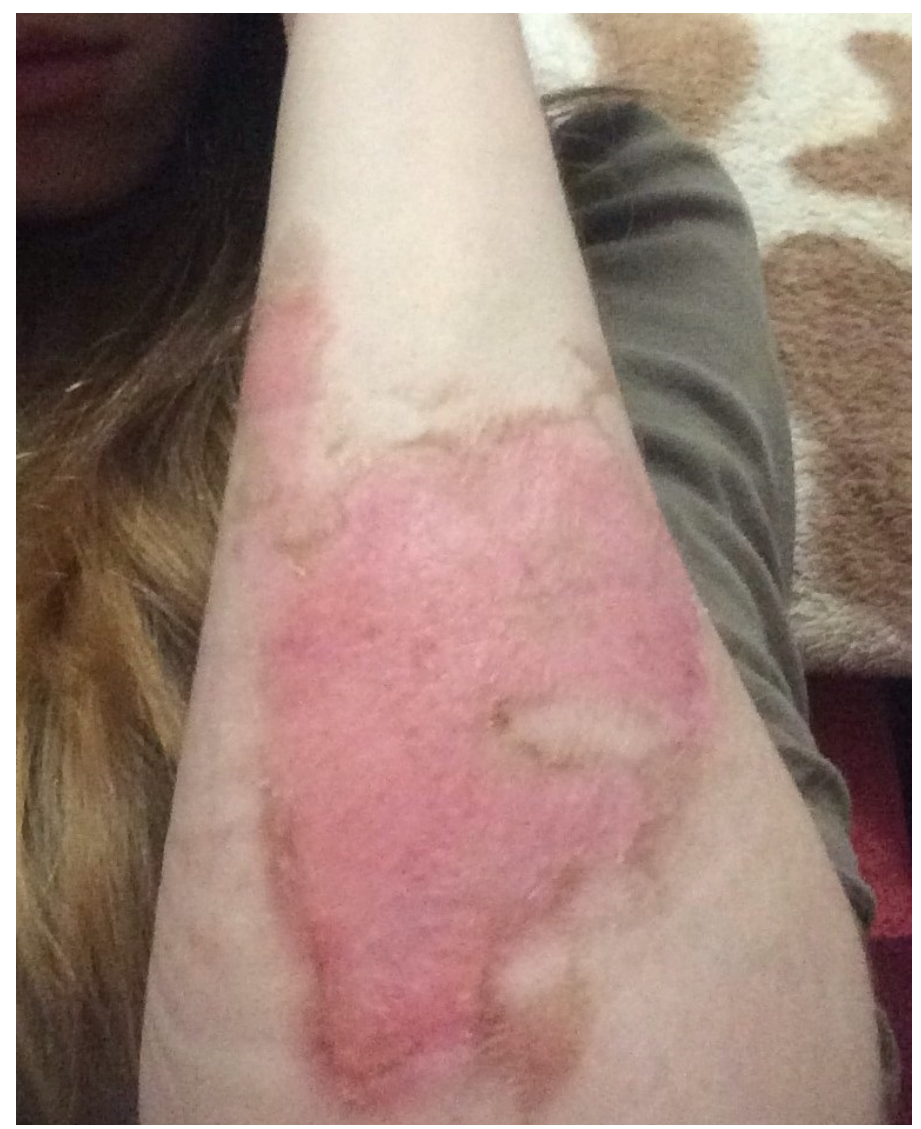

Figure 3. A photograph of the arm taken 7 days after the burn. It shows the continuing healing of the third degree burn areas, with a partial, slight peripheral browning at the margins of the previously necrotic skin. 


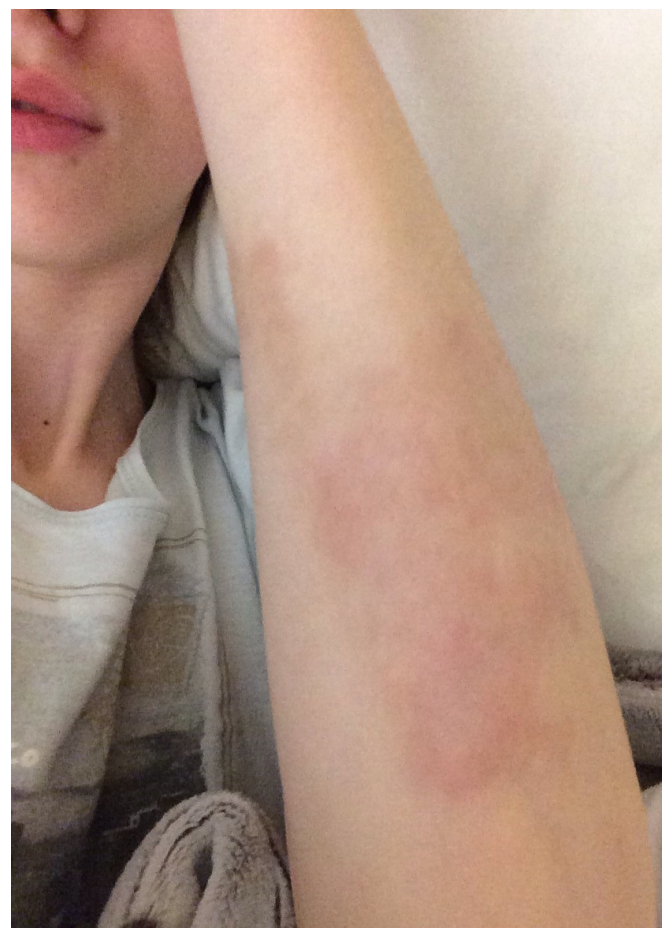

Figure 4. A photograph of the arm at 8 weeks. The original area of the burn is covered by normal appearing skin with minimal underlying areas of increased erythemia. This too eventually disappeared.

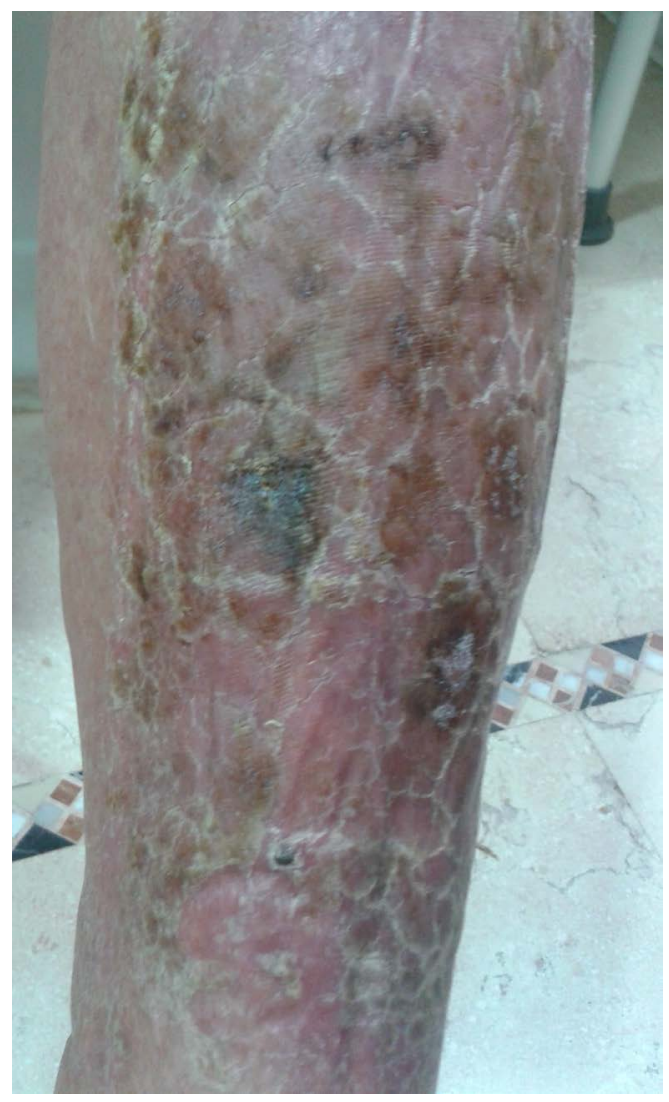

Figure 5. Lower leg showing inflamed, necrotic tissue covering the shin. It was due to chronically impaired vascular supply, attributed to diabetes and hypertension. 


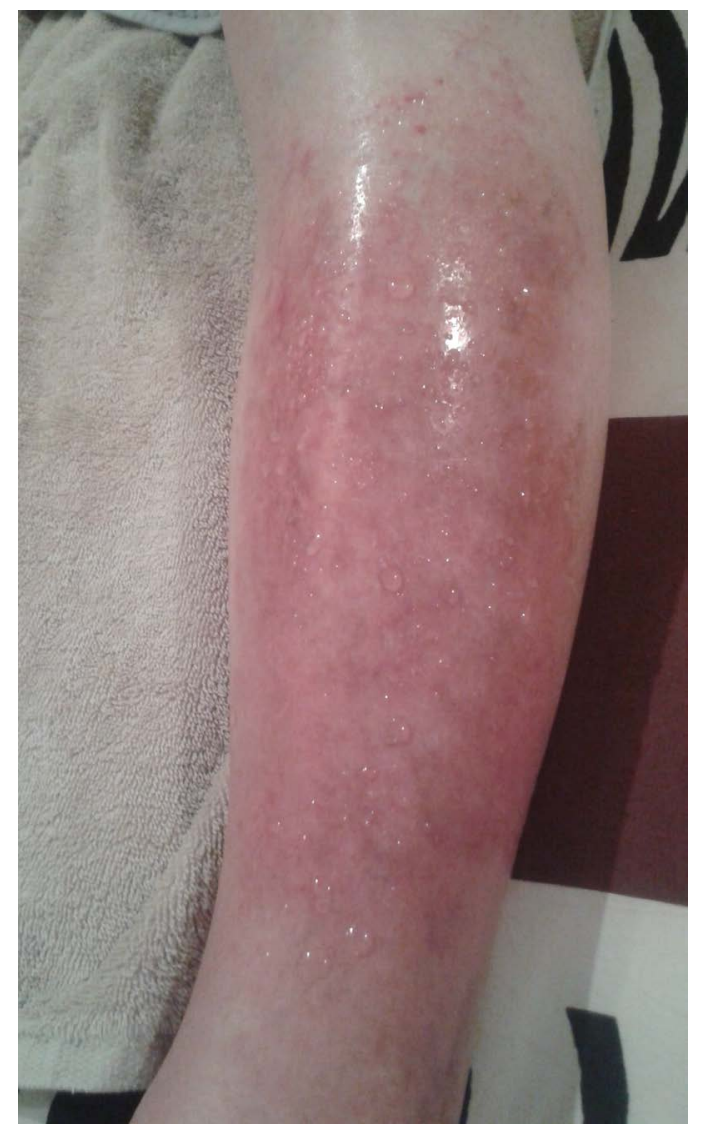

Figure 6. A photograph of the same leg 21 days later, during which time Enercel-mist was applied daily. The necrotic tissue had sloughed off from the leg, revealing a healthyappearing, smooth, new skin covering. The fluid droplets are from the spraying of Enercel-mist.

\subsection{CSC}

As noted above, CSC was originally intended as a disinfectant, especially for Gram positive bacteria, including Methicillin resistant Staphylococcus aureus (MRSA). A goat farmer began to use the solution as an environmental disinfectant in the hope of controlling an outbreak of MRSA infections among a herd of goats. A veterinarian visiting the farm directly applied CSC as a $20 \%$ solution spray to a sick dog, which because of presumptive MRSA skin infection, was scheduled for euthanasia the next day. The euthanasia was cancelled since the skin infection resolved with the single administration. The veterinarian was sufficiently impressed that he decided to use $20 \%$ CSC to irrigate the peritoneal cavity of a goat undergoing caesarian section. The operation was successful and seven offspring (kids) were delivered. CSC was subsequently applied twice daily to the site of surgical incision. Surprisingly, the mother goat was "up and running" by the next day. When examined by the veterinarian 7-days post operatively, he concluded there were no internal adhesions, a very common complication of caesarian sections performed in goats. Even more remarkable, the surgical scar was quite unlike that expected a week after surgery. Instead, the veterinarian remarked that it looked years old. Two weeks later, after three more appli- 
cations of $20 \%$ CSC, the scar was gone and fur had grown back over the incision. As a measure of the health of the adult goat, all seven of her kids survived. This is rather unusual for the offspring of goats subjected to caesarian section.

Individual L.H., age 50, was using an electric screwdriver to install drywall panels onto $2 " \times 4$ " boards. He inadvertently misdirected the screw such that it came through the panel and entered the thumb of his left hand. The screw passed through the front, inner side and thumbnail. It was necessary to reverse the rotation of the screwdriver to withdraw the screw. A gaping hole was left in the front, side and back of his thumb, surrounded by torn flesh. It was nearcertain that the terminal phalange bone was penetrated. Two days elapsed with the thumb becoming very painful, swollen and was beginning to throb. CSC was made available primarily as a potential anti-bacterial therapy. It was sprayed onto the wound at $100 \%$ concentration. Apart from the initial stinging, there were no adverse effects. The individual was instructed to dip his thumb into a 2 oz container of CSC twice daily for 7 days. Remarkably, the wound closed and the swelling and pain resolved within a day of starting CSC treatment. The soft tissue within the thumb continued to heal over the next week, without noticeable scabbing, discoloration or scarring. A new fingernail grew during the second week. His thumb became fully functional and unscarred with a normal appearing thumbprint. A recent photograph of the thumb is shown in Figure 7.

Individual R.B. was hospitalized in 2000 at the age of 48 for a heart attack and congestive cardiac failure. Four-vessel coronary bypass surgery was performed. He acquired a post-operative MRSA infection in his chest wall. This required repeated admissions to the hospital's intensive care unit over the next year for debridement of necrotic tissue and placements of indwelling catheters. Although,

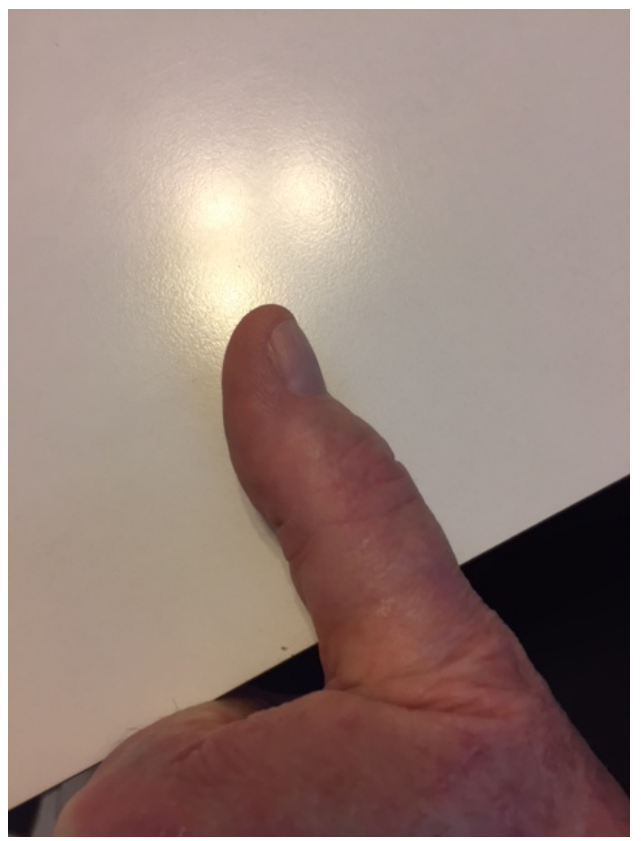

Figure 7. A recent photograph of the thumb that was previously injured with a penetrating screw. There is no deformity of the thumb or any discernable scar tissue. 
the chest infection ultimately resolved, both lower legs and feet became infected with MRSA. Multiple surgeries were performed on the right lower leg and foot, including establishing a vascular anastomosis and amputating a gangrenous toe. A more persisting infection developed in his left lower leg and foot. Surgical therapy included partial removal of the calcaneus (heel bone) and vascular anastomosis. The left foot infection proved to be refractory to many attempts at therapy. These included multiple admissions to the Barnes Jewish Hospital in St. Louis for surgical debridement and vancomycin infusions. He also received repeated sessions of hyperbaric oxygen therapy at Forrest Park Hospital in St. Louis. Pus continued to ooze from a 3-inch long fistula extending up his left leg. On repeated occasions, the inflammation would flare in its severity, necessitating brief hospitalizations for skilled nursing care and intravenous administration of antibiotics. In 2008, he was advised that his only option for survival was amputation of the left foot and lower leg. Furthermore, it was explained that any prosthesis would likely fail because of inevitable recurrence of MRSA at the amputation site. Essentially, he would become wheelchair bound for life. He was not presently able to walk unaided or to put pressure on his left foot. He was provided with undiluted CSC and began to spray the wound and surrounding skin twice daily. This soon resulted in a marked reduction in pain, apart from the short-term stinging effect of the spray on the open tissue. The amount of fluid drainage progressively decreased over the next several weeks and the open wound reduced to less than half of its earlier size. He could once again put pressure on his foot and walk with a supportive boot. The improvements were dramatic and have lasted over several years. For example, he never again found it necessary to seek a hospital admission for a flare-up of his infection. He discontinued taking antibiotics, yet continued the regular use of the CSC spray. The blood circulation to his lower leg also markedly improved and the prior scab tissue in the lower leg was replaced by normal appearing skin. He feels it is probable that the calcaneus has regained some of its former size, although there is still a major tissue defect. On rare occasions, the skin completely covers the heel, but mostly there is a continuing oozing of fluid. Clearly, the heel area and tissue fistula have not completely healed and the individual still self-applies dressings to the wound at $2-3$ day intervals. Nevertheless, with the continuing use of CSC, the wound is far better than before and amputation is no longer under consideration.

\section{Discussion}

Enhancing the ACE pathway can limit the inflammatory reaction to skin tissue damage caused by physical trauma, burns, ischemia, infections and operative incisions. This is of major importance, since skin inflammation and subsequent fibrosis can be inhibitory to the regeneration of specialized skin structures and to the formation of a smooth epithelial skin surface. Skin damage exposes the innate immune system to modified or normally masked self-components, referred to as "danger signals" [5]. Various contaminating microbes can express similar 
cross-reactive molecules. It is proposed that an enhanced ACE pathway increases the resilience of innate immune cells to being triggered by tissue and microbe-derived signals, thereby, raising the threshold to either the initiating or maintaining of an inflammatory response.

The ACE pathway may also directly facilitate the regeneration of more specialized structures within the skin through the provision of added cellular energy. As suggested by the complete recovery of the man's thumb and the possible regrowth of part of the calcaneus in the patient with the foot infection, the enhanced regenerative capacity may extend to the regrowth of bone. Localized electrical stimulation can be useful in the healing of bone fractures [30]. Arguably, the electrical stimulation is also working by enhancing the ACE pathway of bone cells.

It is convenient that energy for the ACE pathway can be provided via KELEA activated water. There are multiple ways in which water can be activated with KELEA [21] [22] [23] [24]. Some of these methods involve the addition of chemicals to the water. The chemicals can be soluble or in the form of insoluble pellets. Activating gases, such as Brown's gas [31] or chlorine dioxide [32] can also be used. Brown's gas includes water molecules that vaporize at room temperature. They can be seen forming during electrolysis as a stream of bubbles arising halfway between the electrodes. Galvanic cells in which electrodes with dissimilar electronegativity are placed in water with electrolytes, and connected by a circuit that allows the intermittent passage of electricity, can similarly be used to activate the water. Other water activating methods simply require placing unopened containers of water into energy fields of increased KELEA [30] [31]. When soluble chemicals are added to water, they can be essentially eliminated by successive dilutions, as in homeopathy [33] or by zero-residue filtration. There are no known complications associated with the use of chemical-free KELEA activated water. The chemicals are, however, retained in CSC because of their anti-bacterial activity, especially against Gram positive bacteria. Except for the intraperitoneal administration of CSC to the goat, this product has not been used parenterally, primarily because of potential chelation of calcium and magnesium. A related product in which ascorbic acid is used rather than citric acid may be more suitable for parental use. Enercel, which is essentially chemicalfree, is applicable for parental use. It can also be consumed as drinking water.

An understanding of the ACE pathway is providing a new paradigm for medicine [34] [35], agriculture [36], industry [37] [38] and basic science [39] [40] [41]. Among the more notable medical applications are:

1) Suppression of infections, including viruses that have deleted or mutated the major antigens normally targeted by the cellular immune system. This immune evasion mechanism is termed stealth adaptation [42] [43]. The brain is particularly susceptible to symptomatic illnesses caused by stealth adapted viruses, with disease examples including autism [44], chronic fatigue syndrome (CFS) [45], and Alzheimer's disease [46]. The ACE pathway is also effective in suppressing HIV which can counteract the immune system by being infectious 
for CD4 lymphocytes [47]. Herpes simplex virus, herpes zoster virus and human papillomavirus have also responded to ACE pathway based therapies [48] [49]. KELEA activated water needs to be evaluated in the therapy of other infections, including Zika virus [50] [51].

2) Promotion of the painless healing of cancer. It can do so by providing the cancer cell with sufficient energy for apoptosis [52]. It might also allow some cancer cells to terminally differentiate.

3) Therapy for medical conditions in which there are impairments in food metabolism. Examples include inefficient respiration as in chronic obstructive pulmonary disease (COPD), impaired blood supply as in cardiovascular and cerebrovascular diseases; metabolic disorders such as diabetes, and increased energy demands as in infections [53].

4) Neurological and psychiatric illnesses in which sets of neuronal cells are apparently either hyperactive or quiescent due to an insufficiency of cellular energy (ICE) from the ACE pathway [54]. An important focus is on the potential therapy of Alzheimer's disease [55].

The present paper adds non-inflammatory tissue healing of the skin to the above list. It will clearly be of interest to include the testing of other skin conditions, such as psoriasis and eczema. Indeed, Enercel is reported to suppress eczema [56] and CSC has alleviated signs and symptoms of severe sunburn and poison oak dermatitis (unpublished). Enercel is also effective in reducing the severity of asthma [56]; again probably by increasing resilience of the innate immune system to being triggered by tissue-derived "danger signals" [5]. Clinical assessments are needed on the ability of an enhanced ACE pathway to limit post-ischemia inflammation and scarring in major organs of the body, including the heart and brain.

\section{Conclusion}

Injury to the skin commonly evokes painful inflammation, which can proceed to disfiguring fibrosis. This can be suppressed by the administration of water with increased dynamic (kinetic) activity. The kinetic activity in the water results from the absorption of an external force termed KELEA (kinetic energy limiting electrostatic attraction). Several means are available for preparing KELEA activated water, including the use of various dipolar compounds. Certain products that were previously identified as being effective homeopathic remedies are likely to function as KELEA activated water with the capacity of enhancing the body's alternative cellular energy (ACE) pathway. KELEA activated water should be readily available in healthcare facilities, ambulances, workplaces and war zones for urgent application to acute injuries of the skin, including burns and physical trauma. Moreover, as described in this paper, KELEA activated water may also help reverse chronic ischemic damage to the skin, which would otherwise lead to amputation. KELEA activated water should also be evaluated in promoting the more complete repair of cellular damage occurring in other organs, particularly the heart and brain. 


\section{Acknowledgements}

Dr. Stephen B. Palmer jointly with the author devised the use of copper-silvercitrate (CSC) as an antibacterial agent to cover both Gram positive and Gram negative bacteria. Dr. Palmer directly participated in the studies showing the tissue healing properties of CSC. He is continuing to teach members of indigenous communities how to best produce CSC. Dr. David Christner of World Health Advanced Technologies, Sarasota, FL, with the assistance of Mr. Sergio Sanseverino, has developed Enercel into a well standardized, therapeutic product for ongoing clinical testing in several areas of the world. Dr. Christner kindly provided information on the two Enercel-treated patients described in this article. Figures 1-6 are also available at http://www.enercel.com. The Institute of Progressive Medicine is a component of MI Hope Inc., a non-profit public charity. Valuable additional clinical input and insights have been received from various Complementary and Alternative Medicine practitioners.

\section{References}

[1] Enoch, S. and Leaper, D.J. (2008) Basic Science of Wound Healing. Surgery, 6, 3137. https://doi.org/10.1016/j.mpsur.2007.11.005

[2] Reinke, J.M. and Sorg, H. (2012) Wound Repair and Regeneration. European Surgical Research, 49, 35-43. https://doi.org/10.1159/000339613

[3] Zhao, R., Liang, H., Clarke, E., Jackson, C. and Xue, M. (2016) Inflammation in Chronic Wounds. International Journal of Molecular Sciences, 17, 2085. https://doi.org/10.3390/ijms17122085

[4] Shanmugam, V.K., Schilling, A., Germinario, A., Mete, M., Kim, P., Steinberg, J. and Attinger, C.E. (2012) Prevalence of Immune Disease in Patients with Wounds Presenting to a Tertiary Wound Healing Centre. International Wound Journal, 9, 403-411. https://doi.org/10.1111/j.1742-481X.2011.00899.x

[5] Matzinger, P. (2002) The Danger Model: A Renewed Sense of Self. Science, 296, 301-305. https://doi.org/10.1126/science.1071059

[6] Eming, S.A., Krieg, T. and Davidson, J.M. (2007) Inflammation in Wound Repair: Molecular and Cellular Mechanisms. Journal Investigative Dermatology, 127, 514525. https://doi.org/10.1038/sj.jid.5700701

[7] Allen, J.E. and Wynn, T.A. (2011) Evolution of Th2 Immunity: A Rapid Repair Response to Tissue Destructive Pathogens. PLoS Pathogens, 7, e1002003. https://doi.org/10.1371/journal.ppat.1002003

[8] Hinz, B. (2016) The Role of Myofibroblasts in Wound Healing. Current Research Translational Medicine, 64, 171-177. https://doi.org/10.1016/j.retram.2016.09.003

[9] Wermuth, P.J., Li, Z., Mendoza, F.A. and Jimenez, S.A. (2016) Stimulation of Transforming Growth Factor- $\beta 1$-Induced Endothelial-to-Mesenchymal Transition and Tissue Fibrosis by Endothelin-1 (ET-1): A Novel Profibrotic Effect of ET-1. PLoS ONE, 11, e0161988. https://doi.org/10.1371/journal.pone.0161988

[10] Bucala, R., Spiegel, L.A., Chesney, J., Hogan, M. and Cerami, A. (1994) Circulating Fibrocytes Define a New Leukocyte Subpopulation That Mediates Tissue Repair. Molecular Medicine, 1, 71-81.

[11] Moulin, V., Larochelle, S., Langlois, C., Thibault, I., Lopez-Vallé, C.A. and Roy, M. (2004) Normal Skin Wound and Hypertrophic Scar Myofibroblasts Have Differential Responses to Apoptotic Inductors. Journal Cell Physiology, 198, 350-358. 
https://doi.org/10.1002/jcp.10415

[12] Nanba, D., Toki, F., Barrandon, Y. and Higashiyama, S. (2013) Recent Advances in the Epidermal Growth Factor Receptor/Ligand System Biology on Skin Homeostasis and Keratinocyte Stem Cell Regulation. Journal Dermatology Science, 72, 81-86. https://doi.org/10.1016/j.jdermsci.2013.05.009

[13] Huysman, E. and Mathieu, C. (2009) Diabetes and Peripheral Vascular Disease. Acta Chirurgica Belgica, 109, 587-594. https://doi.org/10.1080/00015458.2009.11680493

[14] Wolcott, R., Sanford, N., Gabrilska, R., Oates, J.L., Wilkinson, J.E. and Rumbaugh, K.P. (2016) Microbiota Is a Primary Cause of Pathogenesis of Chronic Wounds. Journal Wound Care, 25, S33-S43. https://doi.org/10.12968/jowc.2016.25.sup10.s33

[15] Sarrazy, V.; Billet, F., Micallef, L., Coulomb, B. and Desmoulière, A. (2011) Mechanisms of Pathological Scarring: Role of Myofibroblasts and Current Developments. Wound Repair Regeneration, 19, s10-s15. https://doi.org/10.1111/j.1524-475X.2011.00708.x

[16] Bullard, K.M., Longaker, M.T. and Lorenz, H.P. (2003) Fetal Wound Healing. World Journal Surgery, 27, 54-61. https://doi.org/10.1007/s00268-002-6737-2

[17] Reed, M.J., Cooper, L., Wood, W., Stramer, B. and Martin, P. (2004) Wound Healing and Inflammation: Embryos Reveal the Way to Perfect Repair. Philosophical Transactions of the Royal Society London, 395, 777-784. https://doi.org/10.1098/rstb.2004.1466

[18] Ferguson,M.W. and O'Kane, S. (2004) Scar-Free Healing: From Embryonic Mechanisms to Adult Therapeutic Intervention. Philosophical Transactions of the Royal Society London B: Biological Science, 359, 839-850. https://doi.org/10.1098/rstb.2004.1475

[19] Martin, W.J. (2003) Complex Intracellular Inclusions in the Brain of a Child with a Stealth Virus Encephalopathy. Experimental Molecular Pathology, 74, 179-209. https://doi.org/10.1016/S0014-4800(03)00038-8

[20] Martin, W.J. (2003) Stealth Virus Culture Pigments: A Potential Source of Cellular Energy. Experimental Molecular Pathology, 74, 210-223. https://doi.org/10.1016/S0014-4800(03)00037-6

[21] Martin, W.J. (2014) KELEA Activated Water. Enhancing the Alternative Cellular Energy (ACE) Pathway. In: John Martin, W., Ed., Stealth Adapted Viruses: Alternative Cellular Energy $(A C E)$ \& KELEA Activated Water, Author House, Bloomington, 115-144.

[22] Martin, W.J. (2015) Therapeutic Potential of KELEA Activated Water. International Journal of Complementary \& Alternative Medicine, 1, Article ID: 00001. https://doi.org/10.15406/ijcam.2015.01.00001

[23] Martin, W.J. (2015) KELEA Activation of Water and Other Fluids for Health, Agriculture and Industry. Journal of Water Resource and Protection, 7, 1331-1344. https://doi.org/10.4236/jwarp.2015.716108

[24] Martin, W.J. (2015) Alternative Cellular Energy Pathway Therapy Using KELEA Activated Water. International Journal Complementary \& Alternative Medicine, 2, Article ID: 00051. https://doi.org/10.15406/ijcam.2015.02.00051

[25] Martin, W.J. (2015) KELEA: A Natural Energy that Seemingly Reduces Intermolecular Hydrogen Bonding in Water and Other Liquids. Open Journal of Biophysics, 5, 69-79. https://doi.org/10.4236/ojbiphy.2015.53006

[26] Martin, W.J. (2015) Interacting Light Paths Attract KELEA (Kinetic Energy Limiting Electrostatic Attraction) and Can Lead to the Activation of Water. Open Journal 
of Biophysics, 5, 115-121. https://doi.org/10.4236/ojbiphy.2015.54010

[27] Martin, W.J. (2015) Interactive Electric Fields Can Attract KELEA (Kinetic Energy Limiting Electrostatic Attraction) and Can Lead to the Activation of Water. International Journal Complementary \& Alternative Medicine, 1, Article ID: 00034. https://doi.org/10.15406/ijcam.2015.01.00034

[28] Gant, V.A., Wren, M.W., Rollins, M.S., Jeanes, A., Hickok, S.S. and Hall, T.J. (2007) Three Novel Highly Charged Copper-Based Biocides: Safety and Efficacy Against Healthcare-Associated Organisms. Journal Antimicrobial Chemotherapy, 60, 294-299. https://doi.org/10.1093/jac/dkm201

[29] Martin, W.J. and Palmer, S.B. (2010) Regenerative Wound Healing Using Copper-Silver Citrate Composition. US Patent Application 20100099758.

[30] Aleem, I.S., Aleem, I., Evaniew, N., Busse, J.W., Yaszemski, M., Agarwal, A., Einhorn, T. and Bhandari, M. (2016) Efficacy of Electrical Stimulators for Bone Healing: A Meta-Analysis of Randomized Sham-Controlled Trials. Scientific Reports, 6, 31724. https://doi.org/10.1038/srep31724

[31] Hurtak, J.J. and Hurtak, D. (2014) The History and Future of Brown's Gas. Nexus Magazine, 21, 45-54.

[32] Humble, J.V. (2009) The Medical Miracle Solution of the 21st Century. Osmora Publishing, Montreal, 117.

[33] Marcy, E.E. and Hunt, F.W. (1868) The Homeopathic Theory and Practice of Medicine. William Radde, New York, 942.

[34] Martin, W.J. (2005) Progressive Medicine. Experimental Molecular Pathology, 78, 218-220. https://doi.org/10.1016/j.yexmp.2005.02.001

[35] Martin, W.J. (2016) Deconstructing Medicine. The Alternative Cellular Energy Pathway. British Journal of Medicine \& Medical Research, 11, 1-6. https://doi.org/10.9734/BJMMR/2016/21484

[36] Martin, W.J. (2014) KELEA Activated Water Leading to Improved Quantity \& Quality of Agricultural Crops. Advances in Plants \& Agriculture Research, 2, Article ID: 00033.

[37] Martin, W.J. (2015) Improved Efficiency of Heat Exchange Using KELEA Activated Water. Open Journal of Energy Efficiency, 4, 36-43. https://doi.org/10.4236/ojee.2015.42004

[38] Martin, W.J. (2016) KELEA (Kinetic Energy Limiting Electrostatic Attraction) Can Markedly Improve the Performance of Gasoline and Diesel Fuels in Power Generation and in Transportation. Journal of Transportation Technologies, 6, 148-154. https://doi.org/10.4236/jtts.2016.63014

[39] Martin, W.J. (2016) KELEA (Kinetic Energy Limiting Electrostatic Attraction) May Add to the Measured Weight of an Object. Journal Modern Physics, 7, 461-472. https://doi.org/10.4236/jmp.2016.76048

[40] Martin, W.J. (2016) KELEA (Kinetic Energy Limiting Electrostatic Attraction) Offers an Alternative Explanation to Existing Concepts Regarding Wave-Particle Duality, Cold Fusion and Superconductivity. Journal Modern Physics, 7, 1995-2007. https://doi.org/10.4236/jmp.2016.715176

[41] Martin, W.J. (2016) KELEA, Cosmic Rays, Cloud Formation and Electromagnetic Radiation: Electropollution as a Possible Explanation for Climate Change. Atmospheric and Climate Sciences, 6, 174-179. https://doi.org/10.4236/acs.2016.62015

[42] Martin, W.J., Zeng, L.C., Ahmed, K. and Roy, M. (1994) Cytomegalovirus-Related Sequences in an Atypical Cytopathic Virus Repeatedly Isolated from a Patient with the Chronic Fatigue Syndrome. American Journal of Pathology, 145, 441-452. 
[43] Martin, W.J. (2014) Stealth Adaptation of Viruses: Review and Updated Molecular Analysis on a Stealth Adapted African Green Monkey Simian Cytomegalovirus (SCMV). Journal of Human Virology \& Retrovirology, 1, Article ID: 00020. https://doi.org/10.15406/jhvrv.2014.01.00020

[44] Martin, W.J. (1995) Stealth Virus Isolated from an Autistic Child. Journal Autism Developmental Disorders, 25, 223-224. https://doi.org/10.1007/BF02178507

[45] Martin, W.J. (1996) Severe Stealth Virus Encephalopathy Following Chronic Fatigue Syndrome-Like Illness: Clinical and Histopathological Features. Pathobiology, 64, 1-8. https://doi.org/10.1159/000163999

[46] Martin, W.J. (2015) Stealth Adapted Viruses-Possible Drivers of Major Neuropsychiatric Illnesses Including Alzheimer's Disease. Journal of Neurology \&Stroke, 2, Article ID: 00057.

[47] Dubrov, V., Dubrova, T., Christner, D., Laurent, D. and Martin, W.J. (2015) Alternative Cellular Energy Based Therapy using Enercel ${ }^{\mathrm{TM}}$ in Advanced AIDS Patients Co-Infected with Tuberculosis and Treated in Chernigov, Ukraine. Journal Human Virology \& Retrovirology, 2, Article ID: 00061.

[48] Martin, W.J. and Stoneburner, J. (2005) Symptomatic Relief of Herpetic Skin Lesions Utilizing an Energy Based Approach to Healing. Experimental Molecular Pathology, 78, 131-134. https://doi.org/10.1016/j.yexmp.2004.10.007

[49] Martin, W.J. and Stoneburner, J. (2014) Alternative Cellular Energy (ACE) Pathway Activation as the Mode of Action of Neutral Red Dye Phototherapy of Human Viruses. Journal of Human Virology \& Retrovirology, 1, Article ID: 00019.

[50] Martin, W.J. (2016) Enhancing the Alternative Cellular Energy (ACE) Pathway in the Prevention of Zika Virus Induced Illness. Journal of Human Virology \& Retrovirology, 3, Article ID: 00097.

[51] Martin, W.J. (2016) Proposed Testing of KELEA Activated Drinking Water in Zika Virus Infected Pregnant Women. Journal of Human Virology \& Retrovirology, 3, Article ID: 00104. https://doi.org/10.15406/jhvrv.2016.03.00104

[52] Martin, W.J. (2016) Cancer as an Insufficiency of Cellular Energy (ICE): Therapeutic Approaches Based on Enhancing the Alternative Cellular Energy (ACE) Pathway. International Journal Complementary \& Alternative Medicine, 3, Article ID: 00074. https://doi.org/10.15406/ijcam.2016.03.00074

[53] Martin, W.J. (2016) Insufficiency of Cellular Energy (ICE): The Basis for Many Illnesses Potentially Correctable Using KELEA Activated Water. International Journal Complementary \& Alternative Medicine, 4, Article ID: 00106.

[54] Martin, W.J. (2016) Insufficiency of Cellular Energy (ICE) in Neurons: From Electrical Hyperactivity to Quiescence. International Journal Complementary \& Alternative Medicine, 4, Article ID: 00118.

[55] Martin, W.J. (2017) Insufficiency of Cellular Energy (ICE) May Precede Neurodegeneration in Alzheimer's Disease and Be Treatable Via the Alternative Cellular Energy (ACE) Pathway. Advances in Alzheimer's Disease, 6, 1-12.

[56] Martin, W.J. and Laurent, D. (2015) Homeopathy as a Misnomer for Activation of the Alternative Cellular Energy Pathway: Evidence for the Therapeutic Benefits of Enercel in a Diverse Range of Clinical Illnesses. International Journal Complementary \& Alternative Medicine, 2, Article ID: 00045.

https://doi.org/10.15406/ijcam.2015.02.00045 


\section{Abbreviations}

ACE: Alternative cellular energy,

ICE: Insufficiency of cellular energy,

KELEA: Kinetic energy limiting electrostatic attraction,

CSC: Copper silver citrate solution,

CPE: Cytopathic effect,

MRSA: Methicillin resistant Staphylococcus aureus.

Submit or recommend next manuscript to SCIRP and we will provide best service for you:

Accepting pre-submission inquiries through Email, Facebook, LinkedIn, Twitter, etc. A wide selection of journals (inclusive of 9 subjects, more than 200 journals)

Providing 24-hour high-quality service

User-friendly online submission system

Fair and swift peer-review system

Efficient typesetting and proofreading procedure

Display of the result of downloads and visits, as well as the number of cited articles Maximum dissemination of your research work

Submit your manuscript at: http://papersubmission.scirp.org/

Or contact jicdsa@scirp.org 